\title{
Determination of tranexamic acid in human plasma by UHPLC coupled with tandem mass spectrometry targeting sub-microgram per milliliter levels
}

\author{
Luisa Barreiros $^{\mathrm{a}, \mathrm{b}, *, 1}$, Júlia L. Amoreira ${ }^{\mathrm{a}, 1}$, Sandia Machado ${ }^{\mathrm{a}}$, Sara R. Fernandes ${ }^{\mathrm{a}}$, \\ Eduarda M.P. Silva ${ }^{a}$, Paula Sác, Sibylle Kietaibl ${ }^{\mathrm{d}}$, Marcela A. Segundo ${ }^{\mathrm{a}, * *}$ \\ ${ }^{a}$ LAQV, REQUIMTE, Departamento de Ciências Químicas, Faculdade de Farmácia, Universidade do Porto, Rua de Jorge Viterbo Ferreira 228, 4050-313 Porto, Portugal \\ ${ }^{\mathrm{b}}$ Núcleo de Investigação e Intervenção em Farmácia (NIIF), Centro de Investigação em Saúde e Ambiente (CISA), Escola Superior de Saúde, Instituto Politécnico do Porto, \\ Rua Dr. António Bernardino de Almeida 400, 4200-072 Porto, Portugal \\ ${ }^{c}$ Centro Hospitalar Universitário do Porto, Largo Prof. Abel Salazar, 4099-001 Porto, Portugal \\ d Sigmund Freud Private University and Evangelical Hospital Vienna, Hans-Sachs-Gasse 10-12, 1180 Vienna, Austria
}

Keywords: Plasma Mass spectrometry Drug monitoring Pharmacokinetics Antifibrinolytic

\begin{abstract}
A B S T R A C T
Tranexamic acid (TXA) is an antifibrinolytic drug, with the ability to inhibit lysine binding at plasminogen receptors, used in adult trauma patients with on-going or at risk of significant haemorrhage. To understand the pharmacokinetics and pharmacodynamics of this drug in variable age groups undergoing surgeries with high blood loss, effective methods for determination of TXA in biological samples at sub- $\mu \mathrm{g} \mathrm{mL}{ }^{-1}$ are still required. We describe herein the development and validation of a method based on ultra-high performance liquid chromatography coupled to triple quadrupole-tandem mass spectrometry to quantify TXA in human plasma. An inexpensive, simple and efficient sample clean-up was implemented, not requiring matrix-matching calibration. Sample preparation consisted in protein precipitation using acetonitrile containing $0.5 \%(\mathrm{v} / \mathrm{v})$ formic acid, followed by hydrophilic interaction based chromatographic separation, with elution in isocratic mode using a combination of acetonitrile and water $(75: 25, \mathrm{v} / \mathrm{v})$, with quantification of TXA based on selected reaction monitoring. Good linearity was achieved $\left(r^{2}>0.997\right)$ for TXA concentrations ranging from 30 to $600 \mathrm{ng} \mathrm{mL}^{-1}$, with LOD of $18 \mathrm{ng} \mathrm{mL}^{-1}$ in plasma. The developed method proved to be selective, sensitive, accurate (96.4-105.7\% of nominal values) and precise (RSD $\leq 4.5 \%$ ). TXA was found to be stable in plasma extracts standing $24 \mathrm{~h}$ at room temperature $\left(20^{\circ} \mathrm{C}\right)$ or in the autosampler, and after three freeze-thawing cycles. Mean recovery values of TXA spiked plasma samples were $\geq 91.9 \%$. No significant matrix effects were observed. The proposed methodology was successfully applied to the clinical study of plasma samples recovered during scoliosis surgery of pediatric patients pretreatment with TXA.
\end{abstract}

\section{Introduction}

Tranexamic acid [trans-4-(aminomethyl)cyclohexane-1-carboxylic acid] (TXA, Fig. 1) has been recently included in the World Health Organization (WHO) core list of essential medicines for use in adult trauma patients with on-going significant haemorrhage, or at risk of significant haemorrhage within $8 \mathrm{~h}$ of injury [1]. Despite its recognition as an important antifibrinolytic drug [2-5], there is a lack of pharmacokinetic and pharmacodynamic data for TXA concerning variable age groups undergoing surgeries with high blood loss. Clinical trials performed so far suggest a wide variability in response to TXA and, therefore, the optimum dose and administration schedules of TXA are still subject of research, aiming at a safe inhibition of fibrinolysis in the perioperative period. Hence, effective methods for determination of TXA in biological samples, including detection at low levels, e.g. ng per milliliter levels, are of utmost importance.

Several methods have been proposed for quantification of TXA in biological fluids, including human plasma and serum [6]. Due to the complexity of biological matrices, most of the techniques used to quantify TXA require a careful sample pre-treatment to remove potential interferences, namely proteins and branched-chain amino 


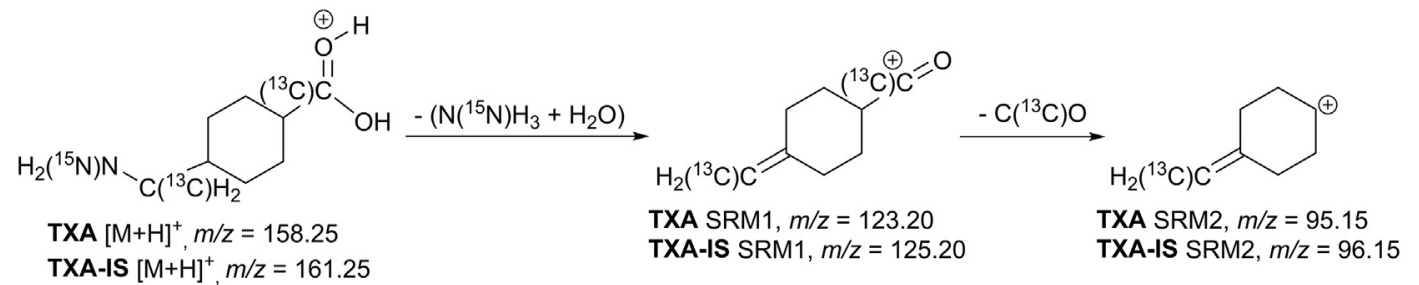

Fig. 1. Structure of pseudo-molecular ion of tranexamic acid (TXA) and corresponding internal standard, the isotopically labeled TXA $\left({ }^{13} \mathrm{C}_{2},{ }^{15} \mathrm{~N}\right.$-TXA).

acids. As TXA has a structural resemblance to amino acids, the concomitant presence of these molecules in biological samples can interfere during preparative separation procedures. In most cases, a deproteinization step with acetonitrile is selected, after addition of an appropriate internal standard (IS) whenever required.

The most commonly used methods for quantification of TXA associate reversed-phase HPLC to fluorescence [7-10] or UV [11-13] detection. Since TXA does not possess in its chemical structure a chromophore or fluorophore, exhibiting therefore a poor absorption at $220 \mathrm{~nm}$, a derivatization step is required. MS detection, however, enables straightforward analyte identification and a tendency to use this technique has been observed in more recent reports [14-22]. Detection limits ranging from 0.01 to $0.5 \mu \mathrm{g} \mathrm{mL}^{-1}$ in blood plasma were so far attained using LC-MS/MS [14,16,18-20,22]. Although LC-MS/MS allows increased sensitivity and the ability to measure down to the $\mathrm{ng} \mathrm{mL} \mathrm{m}^{-1}$ range in complex matrices such as plasma or serum, it still requires attention and development due to issues concerning sample treatment, matrix effects on ion suppression/enhancement, and studies on analyte ionization efficiency.

In this context, the aim of this work was to develop and validate a UHPLC-MS/MS method for the quantification of TXA in human plasma. Minimal sample treatment was pursued for high-throughput applications, aiming also to reduce the manipulation of biological materials. The proposed methodology was successfully applied to the clinical study of samples recovered during scoliosis surgery of pediatric patients dosed with TXA.

\section{Material and methods}

\subsection{Chemicals}

Tranexamic acid and ${ }^{13} C_{2},{ }^{15} N$,trans-tranexamic acid (Fig. 1), used as internal standard (TXA-IS), were purchased from Toronto Research Chemicals Inc. (Toronto, ON, Canada), through LGC standards (Barcelona, Spain). Acetonitrile (LiChrosolv LC-MS grade) and formic acid were acquired from Merck (Darmstadt, Germany). Ammonium bicarbonate (LC-MS grade) was acquired from Fluka (Buchs, Switzerland). Water from arium water purification system (resistivity $>18$ $\mathrm{M} \Omega \mathrm{cm}$, Sartorius, Göttingen, Germany) was used for the preparation of all solutions. Two different mixtures of acetonitrile and water containing $10 \mathrm{mM} \mathrm{NH}_{4} \mathrm{HCO}_{3}, \mathrm{pH} 7.4$ (A and $\mathrm{B}$ ) were used for studying mobile phase composition. Component A consisted of acetonitrilewater-aqueous ammonium bicarbonate $(\mathrm{pH} 7.4 ; 100 \mathrm{mM})(30: 60: 10, \mathrm{v} /$ $\mathrm{v} / \mathrm{v})$ whereas component $\mathrm{B}$ consisted of acetonitrile-water-aqueous ammonium bicarbonate $(\mathrm{pH} 7.4 ; 100 \mathrm{mM})(80: 10: 10, \mathrm{v} / \mathrm{v} / \mathrm{v})$. Prior to use, both mobile phase components were filtered through $0.45 \mu \mathrm{m}$ Millipore (Billerica, MA) HVHP filters and degassed in an ultrasonic bath for $15 \mathrm{~min}$.

\subsection{Preparation of standard solutions}

Stock solutions of TXA and TXA-IS were prepared in water at $1 \mathrm{mg} \mathrm{mL}^{-1}$ and stored at $-20^{\circ} \mathrm{C}$. Intermediate solutions of TXA were prepared daily at 20000 and $1500 \mathrm{ng} \mathrm{mL}^{-1}$ in mobile phase, i.e. acetonitrile-aqueous ammonium bicarbonate ( $\mathrm{pH} 7.4 ; 10 \mathrm{mM})(75: 25, \mathrm{v} / \mathrm{v})$, and further diluted in the same solvent to achieve final concentrations of $30,60,90,150,300,450$ and $600 \mathrm{ng} \mathrm{mL}^{-1}$. The internal standard (TXA-IS) was added to each TXA standard solution in order to obtain a final concentration of $300 \mathrm{ng} \mathrm{mL}^{-1}$.

\subsection{Sample preparation and quality control samples $(Q C)$}

Human plasma samples containing TXA $(100 \mu \mathrm{L})$ were mixed with acetonitrile $(500 \mu \mathrm{L})$, containing $0.5 \%(\mathrm{v} / \mathrm{v})$ of formic acid to precipitate proteins. The samples were then mixed vigorously by vortexing for $30 \mathrm{~s}$ and centrifuged at $18000 \times g$ for $6 \mathrm{~min}$ at $4^{\circ} \mathrm{C}$. Supernatants were collected, TXA-IS was added at $300 \mathrm{ng} \mathrm{mL}^{-1}$ and, lastly, $0.2 \mu \mathrm{L}$ of the extract were injected into the UHPLC-MS/MS for analysis. Whenever required, the supernatant was diluted $20 \times$ in acetonitrile-aqueous ammonium bicarbonate (pH 7.4; $10 \mathrm{mM}$ ) $(75: 25, \mathrm{v} / \mathrm{v})$ before analysis. Quality control (QC) samples at three different levels (low, medium and high) were prepared in mobile phase and in plasma extract at concentrations of 90, 300 and $600 \mathrm{ng} \mathrm{mL}^{-1}$.

\subsection{UHPLC-MS/MS analysis}

Chromatographic analysis was performed in a Nexera X2 UHPLC system comprising two LC-30AD pumps, a DGU-20A5R degassing unit, a SIL-30AC autosampler and a CTO-20AC oven (Shimadzu Corporation, Kyoto, Japan). The MS/MS system was a triple quadrupole LCMS-8040 mass spectrometer equipped with an electrospray ionization source (ESI) (Shimadzu Corporation). The UHPLC-MS/MS system was also equipped with an additional LC-20AD pump and a diverter valve FCV20AH2 (Shimadzu Corporation) that permit to divert to waste non-relevant portions of chromatographic runs, thus minimizing fouling of the ESI probe and sample cone.

A BEH Amide column $(50 \times 2.1 \mathrm{~mm}, 1.7 \mu \mathrm{m}$; Waters, Milford, MA, USA), maintained at $40^{\circ} \mathrm{C}$, was used as stationary phase. The chromatographic separation was performed in isocratic mode using as mobile phase a mixture of acetonitrile-aqueous ammonium bicarbonate $(\mathrm{pH} 7.4 ; 10 \mathrm{mM})(75: 25, \mathrm{v} / \mathrm{v})$, at a flow rate of $0.1 \mathrm{~mL} \mathrm{~min}^{-1}$. The total run time was $8.0 \mathrm{~min}$, with a retention time of $6.4 \mathrm{~min}$ for TXA. During each chromatographic run, the column eluate was diverted to waste from 0 to $5.5 \mathrm{~min}$, directed to MS interface between 5.5 and $7.6 \mathrm{~min}$ and again diverted to waste until $8.0 \mathrm{~min}$.

The MS was operated in positive ionization mode $(\mathrm{ESI}+)$ and data was acquired in selected reaction monitoring (SRM) mode. The product ions monitored for TXA were $m / z 158.25>95.15$ for quantification, and $158.25>123.20$ for identification. ${ }^{13} C_{2},{ }^{15} N$,trans-TXA was employed as internal standard and monitored at $\mathrm{m} / \mathrm{z}$ transitions $161.25>96.15$ and $161.25>125.20$ with similar purposes. The following parameters were used for analysis: nebulizing gas $\left(\mathrm{N}_{2}\right)$ flow rate at $1.5 \mathrm{~L} \mathrm{~min}^{-1}$, drying gas $\left(\mathrm{N}_{2}\right)$ flow rate at $18.0 \mathrm{~L} \mathrm{~min}^{-1}$, desolvation line temperature at $280^{\circ} \mathrm{C}$, heat block temperature at $400{ }^{\circ} \mathrm{C}$, detector voltage at $1.88 \mathrm{kV}$, collision gas (argon) at $230 \mathrm{kPa}$. The injection volume was $0.2 \mu \mathrm{L}$. Peak detection and quantification were performed using LabSolutions software version 5.60 SP2 (Shimadzu Corporation). 


\subsection{Analytical method validation}

The developed UHPLC-MS/MS method was validated for selectivity, linearity and range, precision and accuracy, limits of detection (LOD) and quantification (LOQ), stability, matrix effect, recovery and carryover effect.

\subsubsection{Selectivity}

The interference from endogenous components of the biological matrices or other components in the TXA samples was investigated by analysing six different blanks of each matrix including mobile phase and human plasma [23].

\subsubsection{Carry-over effects}

The possibility of carry-over was assessed by injecting mobile phase, i.e. acetonitrile-aqueous ammonium bicarbonate ( $\mathrm{pH} 7.4 ; 10 \mathrm{mM})$ $(75: 25, \mathrm{v} / \mathrm{v})$ following the analysis of the highest calibration standard $\left(600 \mathrm{ng} \mathrm{mL}^{-1}\right.$ ) and also during sample analysis, following the analysis of 6 consecutive samples.

\subsubsection{Linearity and calibration range}

To evaluate linearity and working range, calibration curves covering the expected therapeutical concentrations were prepared and acquired in triplicate, in three independent analytical runs. Each calibration curve was established by plotting the ratio analyte peak area/IS peak area $v s$. the nominal concentration of TXA standard solutions prepared in mobile phase. Seven concentration levels were used (30, $\left.60, \quad 90, \quad 150, \quad 300,450, \quad 600 \mathrm{ng} \mathrm{m}^{-1}\right)$, corresponding to $0.18-3.6 \mu \mathrm{g} \mathrm{mL}^{-1}$ (dilution 1:6) or to $3.6-72 \mu \mathrm{gL}^{-1}$ (dilution 1:120) in plasma samples. Back calculated concentrations of the calibration standards were determined as recommended by EMA guideline [23]. Furthermore, a blank sample (without analyte and without IS) and a zero sample (only with IS) were included in each analytical run.

\subsubsection{Accuracy and precision}

Accuracy and precision were determined by assaying QC samples at three concentration levels $\left(90,300\right.$ and $600 \mathrm{ng} \mathrm{mL}^{-1}$ of TXA) for mobile phase and human plasma extracts (corresponding to $0.54,1.8$, and $3.6 \mu \mathrm{g} \mathrm{mL}^{-1}$ in plasma and to $10.8,36$, and $72 \mu \mathrm{g} \mathrm{mL}^{-1}$ in diluted plasma (1:20)). The accuracy expressed by percentage of the nominal concentration value, and precision expressed by the coefficient of variation (CV), were calculated as follows: accuracy $(\%)=$ (mean measured concentration/nominal concentration) $\times 100$; precision $(\mathrm{CV}$, $\%)=($ standard deviation $/$ mean $) \times 100$. Intra-day (within-run) values were obtained by replicate analyses $(n=6)$ followed by interpolation in the calibration curve established on the same day. Inter-day (between-run) values were obtained from 3 independent experiments $(n=3)$.

Furthermore, to evaluate if sample dilution affects the accuracy and precision, QC samples were spiked with TXA at a concentration level above the highest calibration standard and diluted to fall within the calibration curve range before analytical determination. Dilution integrity was assayed by spiking $1800 \mathrm{ng} \mathrm{mL} \mathrm{m}^{-1}$ of TXA in mobile phase and plasma extracts and diluting 1:20 in mobile phase before LC-MS/ MS quantification.

\subsubsection{Limits of detection and quantification}

Limit of detection (LOD) and limit of quantification (LOQ) values for TXA in each matrix $(n=10)$ were determined by the signal-to-noise ratio, defined as the concentrations that originated a signal-to-noise ratio of $3: 1$ and 10:1, respectively [24].

\subsubsection{Stability}

Short-term stability at room temperature (RT), freeze and thaw stability and autosampler stability were evaluated in processed samples. The short-term stability of TXA was assessed by maintaining the
QC samples at RT $\left(20 \pm 2{ }^{\circ} \mathrm{C}\right)$ for $24 \mathrm{~h}$. Freeze $\left(-20^{\circ} \mathrm{C}\right)$ and thaw stability of the samples was obtained over three freeze-thaw cycles, by thawing at RT for $2 \mathrm{~h}$ and refreezing for $24 \mathrm{~h}$. Autosampler stability of TXA was assayed by analysis of QC samples, which were stored in the autosampler $\left(+5^{\circ} \mathrm{C}\right)$ of the UHPLC instrument for $24 \mathrm{~h}$. For each concentration and each storage condition, six replicates were analysed in the same analytical batch. The concentration of the target analyte after the storage period was compared to the initial concentration determined for the freshly prepared samples, analysed immediately after preparation.

\subsubsection{Recovery and matrix effect}

The recovery of TXA from human plasma was assessed by spiking plasma samples with TXA and IS before extraction and sample processing, in order to achieve final concentrations of 90 and $300 \mathrm{ng} \mathrm{mL}-1$ TXA in extracts. Sample processing was performed as described in Section 2.3. The percentage of recovery was obtained by comparing the peak area of spiked samples with the peak area of standard solutions prepared at the same concentrations.

Matrix effect was assessed by the post-extraction addition method, using six different blanks of plasma matrix. As recommended, the matrix factor (MF) was calculated for TXA and corresponding IS, by comparing the peak area obtained in spiked blank matrix extracts with the peak area obtained for the same concentration of analyte in mobile phase. Matrix effect was determined at two concentration levels of TXA ( 90 and $300 \mathrm{ng} \mathrm{mL}^{-1}$ ), adding $300 \mathrm{ng} \mathrm{mL}^{-1}$ of TXA-IS in both cases. The IS normalized MF was also determined by dividing the MF of TXA by the MF of the corresponding TXA-IS [23].

\subsection{Application to a clinical study of samples recovered during scoliosis surgery}

The study followed internationally accepted rules of good clinical practices and was approved by the Ethics Committee for Health at Centro Hospitalar do Porto (process no. 2015.083(077-DEFI/072-CES)). All participating subjects have given their written informed consent. Briefly, the patients had an initial bolus of $10 \mathrm{mg} \mathrm{kg}^{-1}$ of TXA during $15 \mathrm{~min}, 15 \mathrm{~min}$ before surgical incision, followed by continuous infusion of $1 \mathrm{mg} \mathrm{kg}^{-1} \mathrm{~h}^{-1}$ from surgical incision to closure of the surgical wound. Blood samples were collected at the end of surgery and $24 \mathrm{~h}$ later for quantification of TXA. Blood samples were collected into EDTA tubes and centrifuged at $3500 \mathrm{rpm}$. The plasma samples (supernatant) were collected and stored at $-20^{\circ} \mathrm{C}$ prior to analysis. After thawing, samples were processed as described in Section 2.3 and analysed by UHPLC-MS/MS. QC samples were run every fifteen injections.

\section{Results and discussion}

Considering the method application to studies of pharmacokinetics and pharmacodynamics, involving pediatric patients under low doses regimen, the main goal of this work was the development of a chromatographic method with low detection and quantification limits, using reduced sample volumes. Furthermore, as a high sample throughput was aimed, a streamlined sample treatment procedure was pursued for straightforward application to LC-MS/MS analysis.

\subsection{Sample preparation}

The plasma samples were initially treated according to the procedure described by Delavenne et al. [19]. This sample preparation method consisted of adding $500 \mu \mathrm{L}$ of acetonitrile containing $500 \mathrm{ng} \mathrm{mL}^{-1}$ of IS to $100 \mu \mathrm{L}$ of sample. This mixture was vortexed during $30 \mathrm{~s}$ and centrifuged at $18000 \times g$ for $6 \mathrm{~min}$ at $4{ }^{\circ} \mathrm{C}$. A volume of $10 \mu \mathrm{L}$ of the supernatant was injected into the LC system, using the same column and solvent system applied in the previously described method. This experiment produced chromatogram peaks with an 
irregular shape and tailing (data not shown), which might indicate the presence of tranexamic acid as different ionic species, along with a poor recovery of the analyte (ca. 20\%). Moreover, these conditions led to a TXA retention time close to the void volume signal, coinciding with the elution of non-retained matrix components, which fosters severe matrix effects.

The TXA molecule contains two ionizable groups in its structure, a carboxyl and an amino group (pKa 4.3 and 10.6, respectively), and is therefore a highly polar compound that exists as a zwitterion at physiological $\mathrm{pH}$. Hence, the success of its extraction from sample is highly dependent on the $\mathrm{pH}$ value. For instance, the predominant form at $\mathrm{pH} 2.6$ is the cationic species whereas at pH5.5 the zwitterion will predominate. Having this in mind, the effect of the addition of formic acid to acetonitrile, with both acting as deproteinization agents, was studied. The use of $0.5 \%(\mathrm{v} / \mathrm{v})$ of this reagent in addition to acetonitrile proved to be the most efficient, allowing recoveries up to $90 \%$ of analyte and greatly enhanced the peak shape. To conclude, this simple and straightforward sample preparation method allows the required sensitivity for clinical studies (as can be seen in Section 3.3), avoiding expensive and time consuming methods namely solid-phase microextraction (SPME) methods [16,18,20,25] or the use of colloidal silica in combination with trivalent cations for phospholipid removal [22].

\subsection{UHPLC-MS/MS method development}

The stationary phase, a BEH Amide column, was selected due to its hydrophilic interaction based mechanism and proven efficiency in the separation of TXA from human plasma [19]. We have first attempted the separation of TXA using the chromatographic method developed by Delavenne et al. [19] that considers elution with acetonitrile-water $(80: 20, \mathrm{v} / \mathrm{v})$ both containing $0.1 \%(\mathrm{v} / \mathrm{v})$ formic acid, at a flow rate of $0.8 \mathrm{~mL} \mathrm{~min}^{-1}$. In these conditions, and using the novel proposed sample treatment procedure, the analyte was not retained in the stationary phase and was eluted with a retention time close to that of matrix interferences. As the inefficient separation causes a reduction of the method's sensitivity, the development of a chromatographic method that permitted the increase of TXA retention time was pursued. As mentioned above, the use of formic acid in the mobile phase leads to the predominance of the cationic form of TXA while for values close to neutral $\mathrm{pH}$, the zwitterionic species form prevails. In this form, both carboxylate and ammonium groups interact with the amide group of the stationary phase leading to an increase of the retention time. Hence, ammonium bicarbonate $\left(\mathrm{NH}_{4} \mathrm{HCO}_{3}\right)$ at $10 \mathrm{mM}(\mathrm{pH}$ 7.4) was tested as an additive of the mobile phase and further studies were performed using this compound.

Subsequently, the effect of aqueous to organic ratio and the flow rate applied were investigated. As expected, the retention time of TXA increased with the percentage of the organic phase. To attain a fast separation while maintaining good separation of TXA from matrix components eluted within the void volume, the proportion of organic to aqueous components in the mobile phase was fixed at 75:25 (v/v). The flow rate applied was also studied in order to maximize sample throughput and minimize mobile phase consumption. The values for TXA retention time were 4.8, 2.4 and $1.2 \mathrm{~min}$ when applying flow rates of $0.1,0.2$, and $0.4 \mathrm{~mL} \mathrm{~min}^{-1}$, respectively. A flow rate of $0.1 \mathrm{~mL} \mathrm{~min}^{-1}$ was selected because, compared to $0.2 \mathrm{~mL} \mathrm{~min}^{-1}$, the lowest flow rate corresponded to an increased analytical signal in the MS detector. Additionally, a better separation of TXA peak from non-retained matrix components was achieved with the lowest flow rate. The subsequent use of the diverter valve as described in Section 2.4 resulted in a TXA retention time of $6.4 \mathrm{~min}$ and a total run of $8.0 \mathrm{~min}$.

Finally, the effect of buffering species in TXA retention time was revisited, applying the above optimized conditions, as shown in Fig. 2. The chromatograms of human plasma samples spiked at $600 \mathrm{ng} \mathrm{mL}^{-1}$ of TXA in final extract, were acquired in SCAN and SRM mode using each additive $\left(\mathrm{NH}_{4} \mathrm{HCO}_{3}\right.$ at $10 \mathrm{mM}(\mathrm{pH} 7.4)$, Fig. $2 \mathrm{~A}$ or $\mathrm{HCOOH} 0.1 \%$
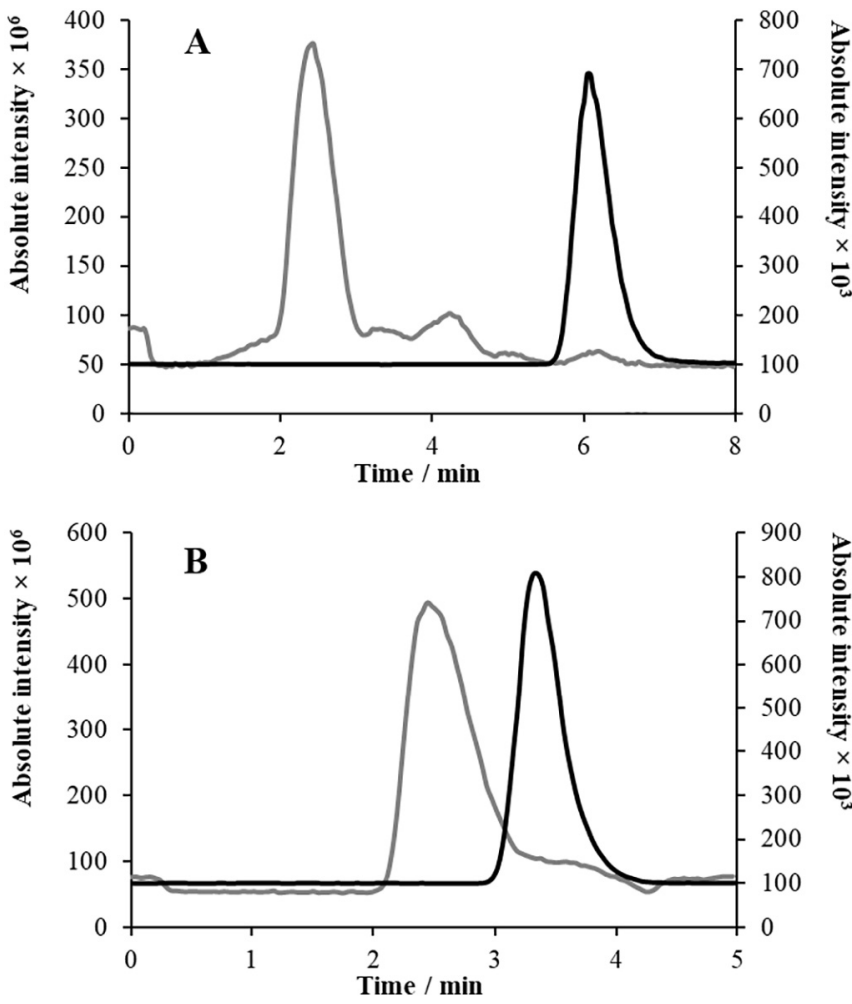

Fig. 2. Chromatogram of plasma spiked with $600 \mathrm{ng} \mathrm{mL}^{-1}$ of TXA in final extract, acquired in SCAN (grey line, left $y$-axis) and SRM modes (black line, right $y$-axis) using ammonium bicarbonate (A) or formic acid (B) as additive of the mobile phase.

(v/v), Fig. 2B) in the mobile phase (acetonitrile-water 75:25, v/v), at a flow rate of $0.1 \mathrm{~mL} \mathrm{~min}^{-1}$. The use of ammonium bicarbonate increased the retention time and allowed, unequivocally, a more efficient separation of the analyte from the matrix interferences reducing, therefore, matrix effects and increasing method sensitivity.

Similarly to other reported MS/MS methods, the ions $[\mathrm{M}+\mathrm{H}]^{+}$ observed in the Q1 spectrum at $m / z 158.25$ and 161.25 were chosen as precursor ion of TXA and TXA-IS, respectively [14,15,17-19]. The most sensitive mass transition observed in TXA product ion spectra, selected for quantification, was from $m / z 158.25$ to 95.15 . A secondary transition from $\mathrm{m} / \mathrm{z} 158.25$ to 123.20 was used for identity confirmation. These product ions result firstly from concomitant loss of water and ammonia (SRM1, Fig. 1) and subsequent loss of carbon monoxide (SRM2, Fig. 1). The corresponding TXA-IS product ions observed at $m / z$ 96.15 and 125.20 (Fig. 1) were selected as quantifying and qualifying ion SRM transitions, respectively. Retention time, quantifying and qualifying ion SRM transitions, as well as optimized collision energies, are presented in Table S1.

\subsection{Method validation}

The selectivity of the proposed UHPLC-MS/MS method was tested in 6 different blank samples of plasma. The overlapping of chromatograms obtained after analysis of blank matrix and from $300 \mathrm{ng} \mathrm{mL}^{-1}$ TXA standard (Fig. S1) showed no interference from endogenous compounds present in samples at TXA and TXA-IS retention time window, for the specified ion transitions. Potential interfering compounds were washed from the column together with the solvent front. Hence, the developed method is selective.

Regression data analysis was performed to establish calibration curves plotted for peak area ratio (TXA/TXA-IS) versus TXA concentration, for an injection volume of $0.2 \mu \mathrm{L}$. The calibration curves (seven concentration points of three replicates each) exhibited good 
Table 1

Accuracy and precision for the analysis of TXA in acetonitrile-aqueous ammonium bicarbonate (pH 7.4; $10 \mathrm{mM})(75: 25$, v/v) and human plasma extracts.

\begin{tabular}{|c|c|c|c|c|c|c|c|}
\hline \multirow[t]{3}{*}{ Matrix } & \multirow[t]{3}{*}{ Nominal concentration (ng $\mathrm{mL}^{-1}$ ) } & \multicolumn{3}{|l|}{ Intra-day } & \multicolumn{3}{|l|}{ Inter-day } \\
\hline & & \multicolumn{3}{|c|}{ Measured concentration } & \multicolumn{3}{|c|}{ Measured concentration } \\
\hline & & $\begin{array}{l}\text { Mean } \\
\left(\mathrm{ng} \mathrm{mL}^{-1}\right)\end{array}$ & $\begin{array}{l}\text { Accuracy } \\
(\%)\end{array}$ & $\begin{array}{l}\text { CV } \\
(\%)\end{array}$ & $\begin{array}{l}\text { Mean } \\
\left(\mathrm{ng} \mathrm{mL}^{-1}\right)\end{array}$ & $\begin{array}{l}\text { Accuracy } \\
(\%)\end{array}$ & $\begin{array}{l}\text { CV } \\
(\%)\end{array}$ \\
\hline \multirow[t]{3}{*}{ Mobile phase } & 90 & 95.1 & 106 & 4.5 & 93.9 & 104 & 7.0 \\
\hline & 300 & 292 & 97.3 & 2.1 & 286 & 95.3 & 2.0 \\
\hline & 600 & 603 & 101 & 2.4 & 589 & 98.2 & 2.6 \\
\hline \multirow[t]{3}{*}{ Plasma } & 90 & 94.2 & 105 & 4.0 & 93.0 & 103 & 6.8 \\
\hline & 300 & 289 & 96.3 & 1.7 & 284 & 94.7 & 1.7 \\
\hline & 600 & 602 & 100 & 2.2 & 586 & 97.7 & 2.8 \\
\hline
\end{tabular}

linearity and were reproducible between 30 and $600 \mathrm{ng} \mathrm{mL}^{-1}$ with coefficient of correlation $r^{2} \geq 0.9974$. Higher concentration values (1000-1200 $\mathrm{ng} \mathrm{mL}^{-1}$ ) were not included in the calibration curve to avoid the introduction of large amounts of TXA in the ESI interface, preventing contamination and loss of sensitivity for low $\mathrm{ng} \mathrm{mL}^{-1}$.

The back calculated concentrations presented deviations within \pm $15 \%$ from the nominal value, meeting the requirements of EMA guideline [23] (results not shown). Sensitivity, assessed as the slope of the calibration curve, presented the mean value of $0.003 \mathrm{ng}^{-1} \mathrm{~mL}$. For human plasma extracts, LOD and LOQ values were 3 and $6 \mathrm{ng} \mathrm{mL}^{-1}$, corresponding to 18 and $36 \mathrm{ng} \mathrm{mL}^{-1}$ in plasma samples, respectively.

Intra- and inter-day precision and accuracy of the TXA assay were estimated at low, medium and high QC concentrations (90, 300, and $600 \mathrm{ng} \mathrm{mL}^{-1}$ ) representative of the calibration range, as depicted in Table 1. Both intra- and inter-day precision and accuracy exhibited values that pass EMA requirements for bioanalytical assay validation [23], i.e., the precision, represented as $\mathrm{CV}$, did not exceed $15 \%$ and the accuracy range was between 85 and $115 \%$. The intra-day precision was $\leq 4.5 \%$ and the accuracy ranged between 96.3 and $106 \%$ of the nominal TXA concentrations. The inter-day precision was $\leq 7.0 \%$ and the accuracy ranged between 94.7 and 104\% (Table 1). Furthermore, dilution of samples did not affect the method accuracy and precision, as both parameters were maintained within the set criteria $( \pm 15 \%)$.

TXA was stable in mobile phase and plasma extracts in all tested conditions as the calculated mean concentrations were within $\pm 15 \%$ of the nominal concentration [23] (Table 2). Short-term stability assessed after $24 \mathrm{~h}$ at room temperature (RT) and after $24 \mathrm{~h}$ in the autosampler at $5{ }^{\circ} \mathrm{C}$ did not show analyte degradation. Accuracy ranges of $88.0-105 \%$ and $99.7-109 \%$, with mean values of $94.7 \pm 7.7 \%$ and $104.0 \pm 3.9 \%$, were determined in these conditions (Table 2). TXA was also found stable in mobile phase and plasma extracts after three freeze-thaw cycles, with accuracy values ranging between 98.5 and $106 \%$ and a mean value of $102.3 \pm 3.1 \%$ (Table 2 ).

The recovery of TXA from plasma samples was evaluated at two QC concentration levels ( 90 and $300 \mathrm{ng} \mathrm{mL}^{-1}$, two replicates each), by spiking plasma harvested from healthy volunteers with TXA and IS before sample processing as described in Section 2.3 (Table 3). Recovery assays of TXA
Table 3

Recovery of TXA and corresponding internal standard from plasma samples.

\begin{tabular}{llllll}
\hline \multirow{2}{*}{$\begin{array}{l}\text { TXA concentration } \\
\left(\mathrm{ng} \mathrm{mL} \mathrm{mL}^{-1}\right)\end{array}$} & \multicolumn{2}{l}{ Recovery (TXA) } & & \multicolumn{2}{l}{ Recovery (IS) } \\
\cline { 2 - 3 } \cline { 6 - 7 } & Mean (\%) & CV (\%) & & Mean (\%) & CV (\%) \\
\hline 540 & 91.9 & 6.2 & & 90.9 & 5.3 \\
1800 & 96.3 & 3.6 & & 94.4 & 1.0 \\
\hline
\end{tabular}

TXA, tranexamic acid; IS, internal standard.

were repeatable ( $\mathrm{CV} \leq 6.2 \%$ ) with mean recovery values of $94.1 \pm 3.1 \%$ whereas for the internal standard (TXA-IS) mean recovery values of $92.6 \pm 2.5 \%$ with $\mathrm{CV} \leq 5.3 \%$ were attained, proving the method suitability for reliable bioanalysis. Moreover, for current process of samples, addition of IS is not required before extraction as recovery values are within recommended levels ( $\geq 85 \%$ ).

The matrix effect of plasma components on the analysis of TXA was evaluated as the percentage ratio between the peak area obtained for post-spiked matrix extracts and the peak area obtained for a standard solution with the same analyte concentration. No significant matrix effect was observed for TXA and corresponding TXA-IS in plasma samples, with mean matrix factor (MF) values of $100.7-110.0 \%$ (Table 4). The application of IS compensated the impact of matrix interferences with IS-normalized MF values of 100.9 and $100.0 \%$ for TXA concentrations of 90 and $300 \mathrm{ng} \mathrm{mL}^{-1}$, respectively. Moreover, the CV of the IS-normalized MF calculated from the 6 lots of matrix for each concentration was within the acceptance criteria $( \pm 15 \%)$ [23]. Therefore, there is no need to establish calibration curves in plasma as recommended by previously reported methods. This feature of the proposed method allows higher sensitivity and decreases the need of maintenance of MS/MS detector.

In summary, the proposed method employs a simple and straightforward sample preparation method, compared to expensive and timeconsuming solid phase extraction method or phospholipid removal $[16,18,20,22]$. Moreover, other previously reported methods based on MS did not use internal standard [16,20] or monitored a single transition $[14,16,20,25]$. The use of ammonium bicarbonate as an additive

Table 2

Stability of TXA in different matrices stored at different experimental conditions.

\begin{tabular}{|c|c|c|c|c|c|c|c|c|c|c|}
\hline \multirow[t]{2}{*}{ Matrix } & \multirow[t]{2}{*}{ Nominal concentration $\left(\mathrm{ng} \mathrm{mL}^{-1}\right)$} & \multicolumn{3}{|c|}{$\begin{array}{l}\text { Measured concentration } \\
\text { ( } 24 \mathrm{~h} \text { at room temperature) }\end{array}$} & \multicolumn{3}{|c|}{$\begin{array}{l}\text { Measured concentrations } \\
(24 \mathrm{~h} \text { in the autosampler) }\end{array}$} & \multicolumn{3}{|c|}{$\begin{array}{l}\text { Measured concentrations } \\
\text { ( } 3 \text { freeze-thaw cycles) }\end{array}$} \\
\hline & & $\begin{array}{l}\text { Mean } \\
\left(\mathrm{ng} \mathrm{mL}^{-1}\right)\end{array}$ & $\begin{array}{l}\text { Accuracy } \\
(\%)\end{array}$ & $\begin{array}{l}\mathrm{CV} \\
(\%)\end{array}$ & $\begin{array}{l}\text { Mean } \\
\left(\text { ng mL }^{-1}\right)\end{array}$ & $\begin{array}{l}\text { Accuracy } \\
(\%)\end{array}$ & $\begin{array}{l}\mathrm{CV} \\
(\%)\end{array}$ & $\begin{array}{l}\text { Mean } \\
\left(\text { ng } \mathrm{mL}^{-1}\right)\end{array}$ & $\begin{array}{l}\text { Accuracy } \\
(\%)\end{array}$ & $\begin{array}{l}\mathrm{CV} \\
(\%)\end{array}$ \\
\hline \multirow[t]{3}{*}{ Mobile phase } & 90 & 94.8 & 105 & 1.7 & 96.6 & 107 & 1.9 & 91.4 & 102 & 4.7 \\
\hline & 300 & 270 & 90.0 & 3.4 & 304 & 101 & 2.6 & 297 & 99.0 & 1.6 \\
\hline & 600 & 554 & 92.3 & 1.9 & 606 & 101 & 1.9 & 629 & 105 & 2.8 \\
\hline \multirow[t]{3}{*}{ Plasma } & 90 & 93.9 & 104 & 3.1 & 98.2 & 109 & 4.8 & 88.6 & 98.5 & 2.6 \\
\hline & 300 & 264 & 88.0 & 1.6 & 299 & 99.7 & 1.9 & 308 & 103 & 4.3 \\
\hline & 600 & 533 & 88.8 & 3.5 & 635 & 106 & 1.5 & 634 & 106 & 2.4 \\
\hline
\end{tabular}


Table 4

Evaluation of matrix effect in the determination of TXA in plasma extracts.

\begin{tabular}{|c|c|c|c|c|c|c|}
\hline \multirow{2}{*}{$\begin{array}{l}\text { TXA } \\
\text { concentration } \\
\left(\mathrm{ng} \mathrm{mL}^{-1}\right)\end{array}$} & \multicolumn{2}{|c|}{$\begin{array}{l}\text { Matrix factor } \\
\text { (TXA) }\end{array}$} & \multicolumn{2}{|c|}{ Matrix factor (IS) ${ }^{\mathrm{a}}$} & \multicolumn{2}{|c|}{$\begin{array}{l}\text { IS normalized } \\
\text { matrix factor }\end{array}$} \\
\hline & $\begin{array}{l}\text { Mean } \\
(\%)\end{array}$ & $\begin{array}{l}\mathrm{CV} \\
(\%)\end{array}$ & Mean (\%) & CV (\%) & Mean (\%) & CV (\%) \\
\hline 90 & 101.6 & 2.5 & 100.7 & 1.4 & 100.9 & 1.6 \\
\hline 300 & 110.0 & 7.6 & 110.0 & 6.3 & 100.0 & 1.4 \\
\hline
\end{tabular}

TXA, tranexamic acid; IS, internal standard.

a IS at constant concentration of $300 \mathrm{ng} \mathrm{mL}^{-1}$.

b IS normalized matrix factor calculated by division of the matrix factor of the analyte by the matrix factor of the IS.

of the mobile phase allowed the quantification of TXA in $6.4 \mathrm{~min}$, with a total run time of $8 \mathrm{~min}$. Other proposed methods attained shorter or equal runs granting, although, LOD/LOQ values higher to those obtained in the present work (40-380 $\mathrm{ng} \mathrm{mL}^{-1}$ and $10-760 \mathrm{ng} \mathrm{mL}^{-1}$ ) [17-19]. The lowest LOD and LOQ values (10 and $\left.20 \mathrm{ng} \mathrm{mL}^{-1}\right)$ reported before in the literature were attained for TXA extracted from $200 \mu \mathrm{L}$ of plasma, a volume 2-fold higher than the one applied in this work [14]. For methods using fluorimetric or UV-Vis detection for quantification of TXA in human plasma samples, higher LOD and LOQ were obtained [6]. Hence, the proposed method has an excellent sensitivity with an LOQ of $6 \mathrm{ng} \mathrm{mL}^{-1}$ in plasma extracts $\left(36 \mathrm{ng} \mathrm{mL}^{-1}\right.$ in plasma) that corresponds to $1.2 \mathrm{pg}$ on column, which is 6 - to 100 -fold lower than the values reported previously [15,16,18-20,25], except for the method reported by Chang et al. [14]. Clinical samples with high concentrations of tranexamic acid can be measured using this method because the upper limit of quantification covers values up to $600 \mathrm{ng} \mathrm{mL} \mathrm{L}^{-1}$ minimizing the need for sample dilution and improving, therefore, method throughput. Nevertheless, if required, dilution does not affect method precision and accuracy as proven by dilution integrity assays.

\subsection{Application to clinical samples recovered during scoliosis surgery}

The developed and validated UHPLC-MS/MS method was applied to evaluate TXA concentration at the end and $24 \mathrm{~h}$ after the surgery. The values for TXA determination in plasma samples are presented in Table 5, along with chromatograms of a blank and a sample containing low level of TXA (Fig. 3). For confirmatory analysis of TXA in samples, a strategy based on 4 identification points was implemented, including one precursor and two product ions [26]. Moreover, to avoid possible interferences and false positives, especially at low level samples, the relative abundance of qualifying (q) to quantifying (Q) ions was monitored. Values of $14.4 \pm 0.5 \%$ were obtained for TXA standards (Table S2) and chromatograms depicting both transitions for TXA at $30 \mathrm{ng} \mathrm{mL}^{-1}$ and for plasma extract are depicted in Fig. S2. The acceptance criteria used for samples was $\pm 30 \%$ as the $\mathrm{q} / \mathrm{Q}$ value was in the

Table 5

Quantification of TXA in plasma samples collected from pediatric patients undergoing idiopathic scoliosis surgery.

\begin{tabular}{lll}
\hline Plasma samples & \multicolumn{2}{l}{ TXA concentration ${ }^{\mathrm{a}}$} \\
\cline { 2 - 3 } & End of surgery $\left(\mu \mathrm{g} \mathrm{mL}^{-1}\right)$ & $24 \mathrm{~h}$ after surgery $\left(\mathrm{ng} \mathrm{mL}^{-1}\right)$ \\
\hline Patient 1 & $11.2 \pm 0.1$ & $219 \pm 2$ \\
Patient 2 & $16.0 \pm 0.1$ & $229 \pm 1$ \\
Patient 3 & $17.1 \pm 0.2$ & $332 \pm 2$ \\
Patient 4 & $14.2 \pm 0.1$ & $226 \pm 6$ \\
Patient 5 & $10.0 \pm 0.1$ & $275 \pm 1$ \\
\hline
\end{tabular}

a Each value corresponds to the mean \pm standard deviation $(n=2)$. Prior to analysis by UHPLC-MS/MS, samples extracts collected at the end of surgery were diluted 20 times in mobile phase.

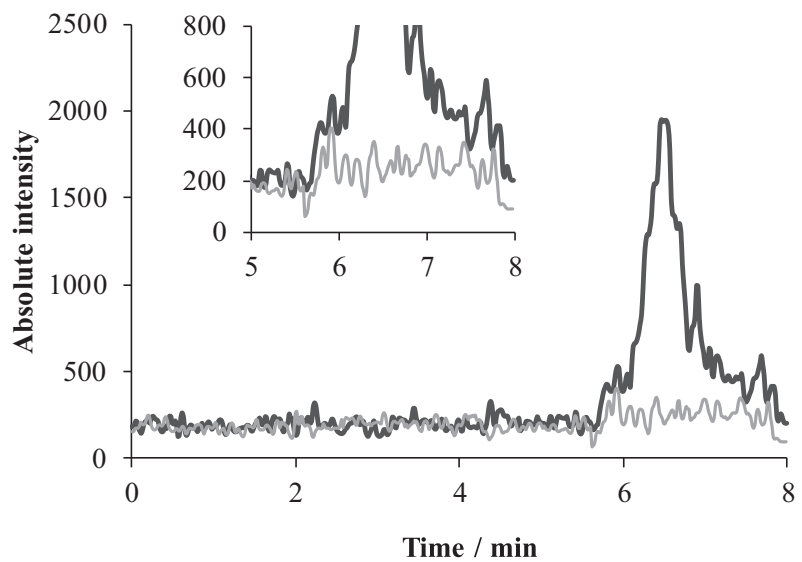

Fig. 3. Overlaid chromatograms of a low concentration plasma sample (24.5 $\mathrm{ng} \mathrm{mL}^{-1}$ TXA in final extract) from pharmacokinetic study (black line) and a blank plasma extract (grey line), with zoom insert on TXA retention time window (6.4 min).

range $10-20 \%$ [26,27]. As shown in Table S3, values were within the acceptance range for all tested samples, including the low level sample depicted in Fig. S2 (\%q/Q = 15.1\%).

Finally, TXA concentration at the end of surgery ranged from $10.0-17.1 \mathrm{~g} \mathrm{~mL}^{-1}$ and from 219 to $332 \mathrm{ng} \mathrm{mL}^{-1} 24 \mathrm{~h}$ after the surgery, representing a decrease of about $65 \times$ in plasmatic concentration. Nevertheless, further correlation of low $\mathrm{ng} \mathrm{mL}^{-1}$ levels of TXA with postoperative haemorrhage are under investigation through data obtained using the proposed quantification method.

\section{Conclusions}

An UHPLC method coupled with tandem mass spectrometry detection was developed and fully validated for quantification of tranexamic acid in human plasma samples. Separation was achieved using a hydrophilic interaction based stationary phase and ammonium bicarbonate in the mobile phase that permitted a more efficient separation of the analyte from the matrix interferences thus reducing matrix effects and increasing method sensitivity. A simple, inexpensive and efficient sample treatment involving protein precipitation with acetonitrile containing $0.5 \%(\mathrm{v} / \mathrm{v})$ formic acid was implemented using reduced sample volumes. The combination of suitable sample treatment, correct $\mathrm{pH}$ adjustment, and efficient chromatographic separation allowed matrix-free calibration. This is an extremely advantageous feature, considering the limited availability of human plasma matrix and the high maintenance cost of MS/MS detector.

The developed UHPLC-MS/MS method proved to be sensitive, selective, accurate and precise for the quantitative analysis of tranexamic acid in human plasma samples, in a wide concentration range. High and consistent recovery values were obtained and potential matrix effects were balanced by the application of an isotopically labeled internal standard. LOD and LOQ values in the $\mathrm{ng} \mathrm{mL}^{-1}$ level were attained, being comparable or even lower than values previously reported in the literature. Moreover, these features could be improved for lower level samples by increasing the injection volume (e.g. $2 \mu \mathrm{L}$ ). The proposed method was found to be suitable for determination of TXA in real plasma samples collected from pediatric patients undergoing scoliosis surgery. 


\section{Acknowledgements}

This work received financial support from the European Union (FEDER funds) and National Funds (FCT/MEC, Fundação para a Ciência e a Tecnologia and Ministério da Educação e Ciência) under the Partnership Agreement PT2020 UID/QUI/50006/2013 - POCI/01/ 0145/FEDER/007265. E. M. P. Silva acknowledges funding from

FEDER - Operational Competitiveness and Internationalization Programme (COMPETE 2020) through project NORTE-01-0145-FEDER000011. L. Barreiros thanks FCT and POCH (Programa Operacional Capital Humano) for her Post-Doc grant (SFRH/BPD/89668/2012). Thanks are also due to Prof. Dra. Margarida Lima, head of Departamento de Patologia Laboratorial, to Dra. Graça Henriques, to Dr. Luis Monteiro, and to all other staff of the Unidade Corelab for cooperation and help in processing the blood samples.

\section{References}

[1] 20th WHO Model List of Essential Medicines (August 2017), http://www.who.int/ medicines/publications/essentialmedicines/20th_EML2017_FINAL amendedAug2017.pdf?ua =1 , Accessed date: 8 July 2018

[2] L. Tengborn, M. Blomback, E. Berntorp, Tranexamic acid - an old drug still going strong and making a revival, Thromb. Res. 135 (2015) 231-242.

[3] C.J. Dunn, K.L. Goa, Tranexamic acid - a review of its use in surgery and other indications, Drugs 57 (1999) 1005-1032.

[4] P.L. McCormack, Tranexamic acid a review of its use in the treatment of hyperfibrinolysis, Drugs 72 (2012) 585-617.

[5] W. Ng, A. Jerath, M. Wasowicz, Tranexamic acid: a clinical review, Anaesth. Intensive Ther. 47 (2015) 339-350.

[6] E.M.P. Silva, L. Barreiros, P. Sá, C. Afonso, S. Kozek-Langenecker, M.A. Segundo, Analytical methods for quantification of tranexamic acid in biological fluids: a review, Microchem. J. 134 (2017) 333-342.

[7] C. Lacroix, P. Levert, G. Laine, J.P. Goulle, Microdetermination of 2 antifibrinolytics (epsilon-aminocaproic acid and tranexamic acid) by liquid-chromatography and fluorimetric detection, J. Chromatogr. 309 (1984) 183-186.

[8] P.M. Elworthy, S.A. Tsementzis, D. Westhead, E.R. Hitchcock, Determination of plasma tranexamic acid using cation-exchange high-performance liquid-chromatography with fluorescence detection, J. Chromatogr. 343 (1985) 109-117.

[9] M. Abrahamsson, Determination of a prodrug of tranexamic acid in whole-blood by reversed-phase liquid-chromatography after precolumn derivatization with fluorescamine, J. Pharm. Biomed. Anal. 4 (1986) 399-406.

[10] J.F. Huertas-Perez, M. Heger, H. Dekker, H. Krabbe, J. Lankelma, F. Ariese, Simple, rapid, and sensitive liquid chromatography-fluorescence method for the quantification of tranexamic acid in blood, J. Chromatogr. A 1157 (2007) 142-150.

[11] K. Matsubayashi, C. Kojima, H. Tachizawa, Determination of tranexamic acid in human-serum by high-performance liquid-chromatography using selective precolumn derivatization with phenyl isothiocyanate, J. Chromatogr. 433 (1988) 225-234.

[12] M.Y. Khuhawar, F.M.A. Rind, HPLC determination of tranexamic acid in pharmaceutical preparations and blood, Chromatographia 53 (2001) 709-711.

[13] G.M. Hadad, A. El-Gindy, W.M.M. Mahmoud, Optimization and validation of an HPLC-UV method for determination of tranexamic acid in a dosage form and in human urine, Chromatographia 66 (2007) 311-317.

[14] Q. Chang, O.Q.P. Yin, M.S.S. Chow, Liquid chromatography-tandem mass spectrometry method for the determination of tranexamic acid in human plasma, $\mathrm{J}$. Chromatogr. B 805 (2004) 275-280.

[15] S. Grassin Delyle, E. Abe, A. Batisse, B. Tremey, M. Fischler, P. Devillier, J.C. Alvarez, A validated assay for the quantitative analysis of tranexamic acid in human serum by liquid chromatography coupled with electrospray ionization mass spectrometry, Clin. Chim. Acta 411 (2010) 438-443.

[16] B. Bojko, D. Vuckovic, E. Cudjoe, M.E. Hoque, F. Mirnaghi, M. Wasowicz, A. Jerath, J. Pawliszyn, Determination of tranexamic acid concentration by solid phase microextraction and liquid chromatography-tandem mass spectrometry: first step to in vivo analysis, J. Chromatogr. B 879 (2011) 3781-3787.

[17] C. Abou-Diwan, R.M. Sniecinski, F. Szlam, J.C. Ritchie, J.M. Rhea, K.A. Tanaka, R.J. Molinaro, Plasma and cerebral spinal fluid tranexamic acid quantitation in cardiopulmonary bypass patients, J. Chromatogr. B 879 (2011) 553-556.

[18] K. Gorynski, B. Bojko, M. Kluger, A. Jerath, M. Wasowicz, J. Pawliszyn, Development of SPME method for concomitant sample preparation of rocuronium bromide and tranexamic acid in plasma, J. Pharm. Biomed. Anal. 92 (2014) 183-192.

[19] X. Delavenne, A. Montbel, S. Hodin, P. Zufferey, T. Basset, Quantification of total and unbound tranexamic acid in human plasma by ultrafiltration liquid chromatography/tandem mass spectrometry: application to pharmacokinetic analysis, J. Pharm. Biomed. Anal. 91 (2014) 32-36.

[20] B. Bojko, D. Vuckovic, F. Mirnaghi, E. Cudjoe, M. Wasowicz, A. Jerath, J. Pawliszyn, Therapeutic monitoring of tranexamic acid concentration: high-throughput analysis with solid-phase microextraction, Ther. Drug Monit. 34 (2012) 31-37.

[21] K.U. Abbasi, M.Y. Khuhawar, M.I. Bhanger, Determination of tranexamic acid using ethyl chloroformate as derivatizing reagent in pharmaceutical preparations and blood by GC, Chromatographia 70 (2009) 1749-1754.

[22] N. Fabresse, F. Fall, I. Etting, P. Devillier, J.C. Alvarez, S. Grassin-Delyle, LC-MS/MS determination of tranexamic acid in human plasma after phospholipid clean-up, J. Pharm. Biomed. Anal. 141 (2017) 149-156.

[23] European Medicines Agency, Guideline on Bioanalytical Method Validation EMEA/ CHMP/EWP/192217/2009, (2011).

[24] ICH guideline Q2(R1), Validation of Analytical Procedures: Text and Methodology, 541 (2005).

[25] M. Wasowicz, A. Jerath, B. Bojko, V. Sharma, J. Pawliszyn, S. McCluskey, Use of a novel technique, solid phase microextraction, to measure tranexamic acid in patients undergoing cardiac surgery, Can. J. Anesth. 59 (2012) 14-20.

[26] European Union, Decision 2002/657/EC 17.08.2002: commission decision laying down performance criteria for the analytical methods to be used for certain substances and residues thereof in live animals and animal products, Off. J. Eur. Communities 221 (2002) 8-32.

[27] F.L. Sauvage, J.M. Gaulier, G. Lachatre, P. Marquet, Pitfalls and prevention strategies for liquid chromatography-tandem mass spectrometry in the selected reaction-monitoring mode for drug analysis, Clin. Chem. 54 (2008) 1519-1527. 